\title{
The effect of strategic complexity on marketing strategy and organizational performance
}

\author{
Stern Neill ${ }^{1}$, Gregory M. Rose*
}

\begin{abstract}
While researchers have examined many antecedents of marketing strategy, there is scant research assessing the effect of organizational cognition. In this study, organizational cognition is examined in terms of the firm's strategic complexity, which is its capacity to integrate multiple environmental dimensions during marketing strategy making. The results from a sample of wholesale distributors reveal four strategic groups that differ based upon their degree of strategic complexity. Results support the proposition that strategic complexity is an organizational capability that enables more effective strategy making and produces superior firm performance.
\end{abstract}

Marketing strategy; Organizational cognition; Performance; Strategic complexity

\section{Introduction}

Organizational competencies such as innovation, flexibility, and responsiveness result from collective cognition or sensemaking. A sustainable competitive advantage derives from the firm's capacity to successfully assimilate, negotiate, and capitalize on complexities in its environment. Marketing performs a key role in an organization's sensemaking efforts through gathering, disseminating, interpreting, and storing activities that seek to understand and act upon the environment (Sinkula, 1994). In this role, marketing potentially shapes and directs the lens through which the organization perceives its strategic situation, and by extension, the actions taken in response.

A fundamental issue for researchers is to understand and explain organizational behavior as pertaining to the deployment of marketing resources for competitive advantage. To address this issue, this study assumes a cognitive perspective by examining an organization's , or ability to simultaneously integrate multiple environmental domains. Organizations can seek to either variety in interpreting their environment by holding multiple and possibly conflicting interpretations or understanding to a single representation (Boisot and Child, 1999).

Effective organizational sensemaking requires tapping into multiple domains and synthesizing the demands of each of these domains in response to changes in the environment. Not only must the organization attend to the market (its customers and competitors), but it also must attend to its internal capabilities (such as its value creation and delivery capabilities) and to changes in its macro-environment (such as changes in the social, technological, economic, and legal forces that impact the organization). Strategically complex organizations construe their environment in a multidimensional way, relating each dimension to the achievement of organizational outcomes (Streufert and Swezey, 1986). This study seeks to relate this capability to effective marketing strategy making and superior firm performance.

\section{The effects of strategic complexity}

To adapt to an environment, a system's internal variety must match or exceed that of its environment (Ashby, 1956). 
Whether the unit of analysis is the individual, group, or organization, the greater the variety and integration of information (e.g., ideas, roles, skills, knowledge), the more environmental stimuli is processed and the greater the variety of decisions and behaviors (Driver and Streufert, 1969). Those organizations that are able to maintain a broad cognitive framework for interpreting their environment are capable of forming a more accurate and complete representation of the situation (Weick and Draft, 1983; Milliken and Martins, 1996).

Research utilizing the cognitive perspective seeks to uncover how organizations come to understand and act upon their environments (Schwenk, 1988), particularly through the use of schema theory (Lyles and Schwenk, 1992; Walsh, 1988, 1995). Schemas influence interpretation by acting as information-seeking structures that accept information and guide action (Neisser et al., 1976). The link between strategy and cognition is based upon the schemas decision-makers hold (e.g., Barr, 1998; Daft and Weick, 1984; Prahalad and Bettis, 1986); and an organization's strategic orientation is an indicator of which environmental aspects an organization believes can provide a competitive advantage (Day and Nedungadi, 1994). Thus, a strategic orientation acts as a schema that selectively and actively modifies experience, enabling organizations to navigate and make sense of the environment.

Strategically complex organizations will consider multiple environmental domains. A complex strategic orientation should enhance decision-making (Boisot and Child, 1999; Weick, 1995), while strategic orientations that are dominated by a single dimension are incomplete (Day and Nedungadi, 1994). For instance, several authors have argued that overemphasis on competition can lead to shortsighted, maladaptive behavior and underperformance (Deshpande and Gatignon, 1994; Urbany and Montgomery, 1998).

By examining the marketing strategy processes and performance of organizations that vary in their degree of strategic complexity, this study investigates the relationship between an organization's strategic complexity, the consid- eration of multiple perspectives in its decision-making, and its capacity to spontaneously make decisions and attain superior performance. Fig. 1 provides an overview of the specific strategic processes and performance variables examined in this study. The basic premise is that an organization's strategic complexity acts as the cognitive framework upon which behaviors are shaped and outcomes are determined.

\section{Marketing strategy processes}

Marketing strategy making includes processes involving both strategy formation and execution (Menon et al., 1999). This study investigates two aspects of marketing strategy: multiple perspective consideration and improvisation. Multiple perspective consideration is defined as the ability to simultaneously incorporate multiple problem-definitions, alternatives, and selection criteria when developing a marketing strategy. Strategic complexity (a focus on multiple dimensions in the environment) provides the foundation for engaging in multiple perspective consideration (examining diverse information and considering multiple alternatives) when making decisions. Although the two are closely related, strategic complexity examines the overall orientation or focus of the firm, while multiple perspective consideration examines the process by which a firm develops its marketing strategy. Past research has argued that as an organization gains the capacity to interpret its environment in a multidimensional way, the breadth of its decision-making processes become more elaborate (Lyles and Schwenk, 1992; Miller et al., 1998; Streufert and Swezey, 1986). That is, strategically complex organizations hold multiple goal orientations and should consider multiple perspectives in their decision-making. Strategically simple organizations, in contrast, should focus on fewer relevant dimensions and apply simple rules in decision-making.

Attending to multiple environmental dimensions, however, does not necessarily correspond to an inability to act.

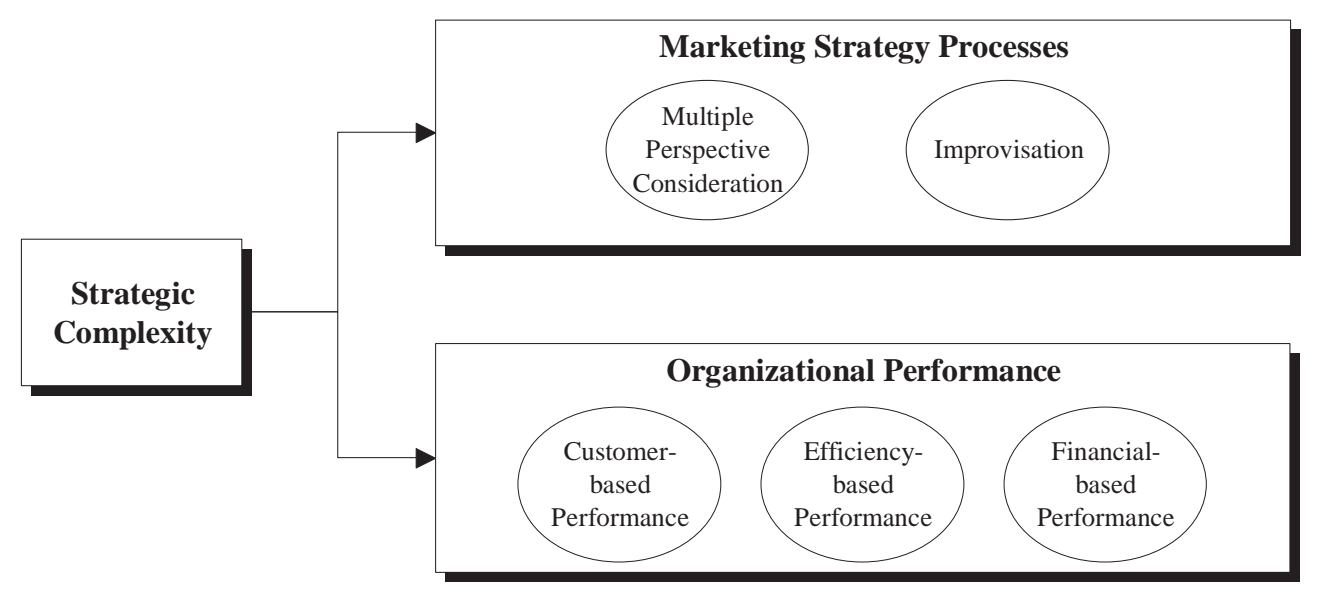

Fig. 1. The effects of strategic complexity on marketing strategy processes and organizational performance. 
Research on cognitively complex managers demonstrates that they are better able to discern patterns and expedite intelligence, design, and choice activities (Wally and Baum, 1994). In this study, the interest is the organization's ability to improvise. Organizational improvisation is the extent to which the formation and implementation of marketing strategy occurs simultaneously (Moorman and Miner, 1998). Strategically complex organizations should be better able to quickly relate, integrate, and process multiple factors influencing the firm's success, allowing them the flexibility to implement strategies while they are formed. In other words, strategically complex organizations should be better able to see how information, actions, and outcomes fit (even if only tentatively) and to both think and act simultaneously. Thus, strategic complexity should be positively related to improvisation.

P1. Strategically complex organizations engage in more (a) multiple perspective consideration and (b) improvisation than strategically simple organizations.

\section{Organizational performance}

Streufert and Nogami (1989) argue that "cognitive complexity is needed wherever uncertainty and situational flux prevail, especially where multifaceted task components and environmental demands require frequent readaptation" (p. 107). Complex managers are more effective at strategic activities, because less cognitively complex managers may apply unidimensional strategies to complex situation (McGill et al., 1994; Streufert and Nogami, 1989). Marketing strategy research has failed to establish a consistent link between single orientations (e.g., customers or products) and business performance (Deshpande et al., 1993; Voss and Voss, 2000). Firm's with dual orientations (e.g., customers and competitors) consistently achieve higher performance (Narver and Slater, 1990; Wright et al., 1991), but previous research, as noted by several authors (Day and Nedungadi, 1994; Kohli et al., 1993), has narrowly focused on the effect of two external dimensions (customers and competitors). A notable exception is recent research by Noble et al. (2002), which demonstrates a positive link between a combined competitor and selling orientation and firm performance.

In this study, organizational performance is judged on multiple dimensions: customer, efficiency, and financial. Day and Nedungadi (1994) argue that how an organization evaluates performance is dependent on the working mental model of its managers. Focusing on a single dimension, like focusing on a single strategy, often precludes the firm from performing well on multiple dimensions (Walker and Ruekert, 1987). Integrating multiple dimensions, in contrast, should produce holistic, adaptive strategies better tailored to the environment. Thus, strategically complex organizations are expected to achieve positive performance outcomes in the customer, efficiency, and financial domains.

P2. Strategically complex organizations have higher levels of (a) customer-, (b) efficiency-, and (c) financialbased organizational performance than strategically simple organizations.

\section{Methodology}

To empirically test the hypotheses, multi-item scales were used for each of nine constructs. Six of the measures were based on prior research, and three were developed for this study. The psychometric properties of the measures were assessed using data gathered from business executives charged with the development and implementation of organization-level strategic marketing decisions. Cluster analysis was used to form distinct groups based upon the degree of emphasis that an organization placed upon four strategic dimensions: (a) competitors, (b) customers, (c) products, and (d) the macro-environment. These four dimensions were chosen based on a review of the literature and previous conceptualizations of the major environmental factors considered in formulating strategic decisions (e.g., Aaker, 2001; Boulding et al., 1994). A one-factor multivariate analysis of variance (MANOVA) was used to test for differences in marketing strategy processes and organizational performance across the groups.

Strategic complexity is composed of the degree that an organization is oriented toward its customers, competitors, products, and macro-environment. These same dimensions are identified by Boulding et al. (1994) as the cognitive framework for strategic decision-making. A customer orientation emphasizes the interests of target buyers, while a competitor orientation focuses on current and potential competitors. The customer and competitor orientation measures used in this study are validated scales based on research by Narver and Slater (1990). Product orientation is an internal orientation emphasizing quality and efficiency of value offerings. Prior research on product orientation has sought to examine its effect on strategic factors and organizational performance, particularly in the areas of quality (Jacobson and Aaker, 1987; Morgan and Piercy, 1998; Parasuraman et al., 1985), efficiency (Piercy, 1998; Wright et al., 1991), and product innovation (Voss and Voss, 2000). A macro-environmental orientation is an organizational focus on monitoring, responding, and capitalizing on issues and trends beyond the organization's immediate industry. Recent research has begun to examine the relationship between a macro-environmental focus, strategic marketing actions, and outcomes, particularly in 
the areas of macro-environmental knowledge (Andrews and Smith, 1996) and technological orientation (Gatignon and Xuereb, 1997). Items for all measures are contained in Appendix A.

Multiple perspective consideration involves the discussion of multiple issues during the decision-making process. Following the work of Mintzberg et al. (1976), the tendency of an organization to incorporate multiple inputs and diverse information is measured at each of three stages: identification, development, and selection. Organizational improvisation is a semantic differential scale developed by Moorman and Miner (1998); it gauges the extent to which the composition and execution of the organization's marketing strategy converge in time.

Performance is assessed based on three sets of items that tap customer-, efficiency-, and financial-based performance. Past research has advocated the use of multiple rather than single measures of organizational performance (Naman and Slevin, 1993; Siguaw et al., 1998). Day and Wensley (1988) argue for a customer-based measure of performance, which they maintain should precede the more frequently used, financial measures. The efficiency- and financial-based performance items used in this study are adapted from Lusch and Brown's (1996) measure of business performance. Respondents are asked to rate their organization's performance over the last year relative to others in their industry.

The sampling frame is drawn from wholesale-distributors in three industries, Beauty and Barber Supply Institute (BBSI), Independent Medical Distributors Association (IMDA), and National Association of Electrical Distributors (NAED). These three associations represent 1055 domestic distributors $(\mathrm{BBSI}=337, \mathrm{IMDA}=99$, and NAED $=619$ ). Wholesale-distributors operate in a dynamic environment brought on by shifts in information technology and industry structure (Distribution Research and Education Foundation, 1998). These three were chosen because they provided a range of product types, technical complexity, and customer type (i.e., industrial vs. consumer). Of 1055 surveys distributed, 261 were returned. To ensure that the relationships among the dependent variables were not different across the three distributor groups, a Box test was performed. The statistic was not significant (Box's $=15.36,20,16230=0.73$, $=0.80$ ), indicating that it was appropriate to combine the sample.

The questionnaire instructed the key informant to focus on recent strategic marketing decisions in their organization. This request was made in that a recent incident is more salient and provides clarity. As this research tests across subjects and not decision types, it is critical that subjects focus on the same type of decision (i.e., strategic rather than operational decisions). Informant competence was evaluated along three criteria. All key informants included in this study had to (1) engage in strategic planning to a considerable extent, (2) hold at least a division manager position, and (3) have more than 5 years of experience with the target organization (cf. Day and Nedungadi, 1994; Menon et al., 1999). Based on these criteria, 57 respondents were deemed unqualified and removed from the study, leaving a usable response rate of $19.3 \%$. The remaining 204 responses were used to assess the measures and propositions.

It should be noted that managers were requested to report self-perceptions of organizational phenomena. Relying on an individual's perception may introduce a potential bias (Phillips, 1981); however, Miller et al. (1998) demonstrate fairly consistent results when analyzing a single top-level executive versus aggregating group perceptions. Therefore, reliance on single-informant perceptions was deemed to be feasible.

Three scales were developed for this study: product orientation, macro-environmental orientation, and multiple perspective consideration. Following established guidelines (Clark and Watson, 1995; Netemeyer et al., 2003), a rigorous procedure was used in the formation of these scales including a preliminary assessment using a separate sample of 88 informants with at least moderate involvement in strategic planning decisions. Assessment began with an examination of each item's distribution. Those items with sufficient variance were retained for further analysis. Next, each scale's unidimensionality was established by examining the inter-item correlations and using factor analyses of related measures (i.e., cognition, marketing strategy, and performance). This approach was chosen over that of a single measurement model due to the small number of observations to indicators, which is recommended to be 5:1 (Raykov and Widaman, 1995). Discriminant validity was assessed by ensuring that the square of the parameter estimate between two constructs $\left(\phi^{2}\right)$ is less than the average variance extracted (AVE) from the constructs examined (Fornell and Larcker, 1981).

To determine the strategic orientations, the summed items of each of the four strategic dimensions were input into a cluster analysis. The clustering variables were standardized prior to analysis. A hierarchical procedure, using Ward's method, was employed to determine the number of groups based on the degree of similarity. Determining the number of clusters was based on the agglomeration coefficient, which allows the researcher to assess the distance between clusters at each successive step (Hair et al., 1998). A large increase indicates the formation 
Table 1

Internal consistency measures for measurement model

\begin{tabular}{llll}
\hline Scale & $\begin{array}{l}\text { Composite } \\
\text { reliability }\end{array}$ & AVE & Mean (S.D.) \\
\hline Competitor orientation & 0.72 & 0.47 & $5.43(0.99)$ \\
Customer orientation & 0.83 & 0.50 & $5.66(0.82)$ \\
Product orientation & 0.76 & 0.52 & $5.74(0.87)$ \\
Macro-environmental orientation & 0.86 & 0.56 & $4.14(1.15)$ \\
Multiple perspective consideration & 0.92 & 0.56 & $5.24(0.94)$ \\
Improvisation & 0.83 & 0.62 & $4.29(1.28)$ \\
Customer-based performance & 0.80 & 0.58 & $5.58(0.80)$ \\
Efficiency-based performance & 0.75 & 0.52 & $4.61(1.16)$ \\
Financial-based performance & 0.83 & 0.63 & $4.68(1.15)$ \\
\hline
\end{tabular}

of a heterogeneous combination. -means clustering was used to determine the final cluster membership, because this technique has proven robust in producing distinct, nonoverlapping clusters (Milligan and Cooper, 1987).

\section{Results}

The item distribution and factor loadings of individual factors were initially examined and were acceptable. Next, the constructs were modeled as first-order factors in LISREL VIII using the covariance matrix as input. This allowed for examination of both within- and across-factor loadings and measurement error. The fit for each model is as follows: cognitive dimensions $\left(\chi^{2}=219.19\right.$ with 98 , $<0.01$; standardized root mean square residual $(\mathrm{SRMR})=0.06$; Tucker-Lewis index $(\mathrm{TLI})=0.90$; comparative fit index $(\mathrm{CFI})=92)$; marketing strategy processes $\left(\chi^{2}=83.74\right.$ with $53,<0.01 ;$ SRMR $=0.04 ;$ TFI $=0.97$; $\mathrm{CFI}=0.98)$, and organizational performance $\left(\chi^{2}=99.72\right.$ with $24,<0.01 ; \mathrm{SRMR}=0.08 ; \mathrm{TFI}=0.86 ; \mathrm{CFI}=0.90)$. As further evidence of model fit and internal consistency, the reliabilities and AVE estimates along with the mean and standard deviation for each construct are reported in Table 1. Composite reliability ranges from 0.72 to 0.92 . Each construct has an AVE estimate above 0.45. Additionally, discriminant validity was supported in all cases.

From the Ward's method results, the agglomeration coefficient indicated a rather large percentage increase going from four to three clusters indicating the formation of a heterogeneous combination. As such, the four-cluster solution was selected for subsequent analysis using the means approach. The standardized mean values for each group along the organizational cognitive dimensions are reported in Table 2. The one-way analysis of variance results indicate that cluster analysis succeeded in generating distinct groups with an overall Wilk's lambda statistic of $0.08(=67.37 ; \quad=12,514 ;<0.01)$. These results are summarized in Table 2.

The four clusters represent organizational strategic orientations that differ in their level of complexity. Cluster 1 represents $29 \%$ (58 organizations) of the sample. This group scores highly across all four dimensions. As such, this group is the most strategically complex and is labeled. The other three groups represent simpler orientations. Group 2 (50 organization or $25 \%$ ) scores highly on two dimensions (customers and competitors) and is labeled in accordance with previous research by Narver and Slater (1990). Group 3 (62 organizations or $31 \%$ ) emphasizes a single dimension, the macro-environment, and is labeled . The fourth cluster is the smallest, representing 30 organizations and $15 \%$ of the sample. It places a low emphasis on all of the dimensions and is labeled Thus, organizations do appear to vary in their degree of strategic complexity.

Table 2

\begin{tabular}{|c|c|c|c|c|}
\hline \multicolumn{5}{|c|}{ Multivariate and univariate analysis of variance results } \\
\hline Dependent variable & Wilk's lambda & -value & Eta squared & Significant contrasts ${ }^{\mathrm{a}}$ \\
\hline Multivariate & 0.08 & $67.37^{\mathrm{b}}$ & - & \\
\hline \multicolumn{5}{|l|}{ Univariate } \\
\hline Competitor & - & $100.19^{\mathrm{b}}$ & 0.60 & $1-2,1-3,1-4,2-3,2-4,3-4$ \\
\hline Customer & - & $124.34^{\mathrm{b}}$ & 0.65 & $1-2,1-3,1-4,2-3,2-4,3-4$ \\
\hline Product & - & $75.59^{\mathrm{b}}$ & 0.54 & $1-2,1-3,1-4,2-4,3-4$ \\
\hline Macro-environmental & - & $116.94^{\mathrm{b}}$ & 0.64 & $1-2,1-3,1-4,2-3,3-4$ \\
\hline \multicolumn{5}{|c|}{ Organizational cognition dimensions: standardized means } \\
\hline Strategic orientation & Cluster 1: Complex & Cluster 2: Simple (Market) & Cluster 3: Simple (Macro) & Cluster 4: Reactive \\
\hline Competitor & 0.81 & 0.43 & -0.40 & -1.44 \\
\hline Customer & 0.88 & 0.36 & -0.32 & -1.54 \\
\hline Product & 0.91 & 0.05 & -0.21 & -1.35 \\
\hline Macro-environmental & 0.97 & -0.85 & 0.30 & -0.97 \\
\hline
\end{tabular}

${ }^{a}$ Significant contrasts ( $<0.05$ ): 1=Complex, 2=Simple (Market), 3=Simple (Macro), 4=Reactive.

b $<0.05$. 


\begin{tabular}{|c|c|c|c|c|}
\hline \multicolumn{5}{|c|}{ Multivariate and univariate analysis of variance results } \\
\hline Dependent variable & Wilk's lambda & -value & Eta squared & Significant contrasts ${ }^{\mathrm{a}}$ \\
\hline Multivariate & 0.54 & $8.27^{\mathrm{b}}$ & - & \\
\hline \multicolumn{5}{|l|}{ Univariate } \\
\hline Multiple perspective consideration & - & $63.22^{\mathrm{b}}$ & 0.33 & $1-2,1-3,1-4,2-4,3-4$ \\
\hline Improvisation & - & $16.97^{\mathrm{b}}$ & 0.09 & $1-4,2-4,3-4$ \\
\hline Customer-based performance & - & $40.30^{\mathrm{b}}$ & 0.21 & $1-2,1-3,1-4,2-4$ \\
\hline Efficiency-based performance & - & $9.88^{\mathrm{b}}$ & 0.06 & $1-4$ \\
\hline Financial-based performance & - & $14.15^{\mathrm{b}}$ & 0.08 & $1-2,1-4$ \\
\hline \multicolumn{5}{|l|}{ Dependent variables: standardized means } \\
\hline Dependent variable & Complex & Simple (Market) & Sin & Reactive \\
\hline Multiple perspective consideration & 0.69 & 0.16 & -0 & -1.03 \\
\hline Improvisation & 0.30 & 0.04 & & -0.62 \\
\hline Customer-based performance & 0.55 & 0.09 & -0 & -0.73 \\
\hline Efficiency-based performance & 0.34 & -0.10 & -0 & -0.32 \\
\hline Financial-based performance & 0.38 & -0.23 & -0 & -0.39 \\
\hline
\end{tabular}

a Significant contrasts $(<0.05)$ : 1=Complex, 2=Simple (Market), 3=Simple (Macro), 4=Reactive.

b $<0.05$.

Table 3 summarizes the MANOVA results and Table 4 provides a qualitative description of the four orientations. The overall Wilk's lambda statistic was $0.54(=8.27$;

$=15,502 ;<0.01)$, thus indicating that the combined dependent variables differ across the four groups. The univariate tests and the corresponding significant contrasts indicate mixed support for P1 and P2. The standardized cell means for each of the four groups are also presented in Table 3.

Overall, the results suggest that strategic complexity affects marketing strategy making and organizational performance. As posited in $\mathrm{P} 1 \mathrm{a}$, organizations with more complex strategic orientations tend to consider multiple perspectives in their decisions. The group is also generally more likely to improvise during strategy making than the group, partially supporting P1b. However, no significant differences in improvisation were found bet- ween the and the also partially supported. The

or

group. P2 was group outperformed the other three groups on customer-based performance (P2a). However, there was mixed support on efficiency(P2b) and financial- (P2c) based performance, with the group performing better than the

group on

efficiency-based performance and outperforming both the and groups on financial performance.

\section{Discussion}

Strategic situations are, by their nature, complex. Confronted with a strategic issue, organizations may activate certain orientations, which serve to shape perceptions and actions. Organizations that develop a multifaceted interpretative capability are able to perceive complex environmental patterns in order to develop and implement effective solutions. Simplified worldviews may result in marketing strategies that fail to encompass and respond to

Table 4

Qualitative profile of strategic orientations

\begin{tabular}{|c|c|c|c|c|}
\hline & Complex & Simple (Market) & Simple (Macro) & Reactive \\
\hline$\%$ of Sample & $29 \%$ & $25 \%$ & $31 \%$ & $15 \%$ \\
\hline \multirow[t]{2}{*}{$\begin{array}{l}\text { Decision-making } \\
\text { process }\end{array}$} & $\begin{array}{l}\text { Synergistically consider multiple } \\
\text { dimensions in decision-making, } \\
\text { including their customers, } \\
\text { competitors, product capabilities, } \\
\text { and changes in their } \\
\text { macro-environment. }\end{array}$ & $\begin{array}{l}\text { Focus primarily on } \\
\text { market-oriented } \\
\text { aspects (i.e., customers } \\
\text { and competitors) of their } \\
\text { environment. }\end{array}$ & $\begin{array}{l}\text { Focus primarily on broad } \\
\text { changes in the macro- } \\
\text { environment, including } \\
\text { changes in the social, } \\
\text { technological, economic, } \\
\text { and legal environment. }\end{array}$ & $\begin{array}{l}\text { Reactive decision-making } \\
\text { with a low level of } \\
\text { attention paid to monitoring } \\
\text { or managing any dimensions } \\
\text { of the environment. }\end{array}$ \\
\hline & $\begin{array}{l}\text { Engage in high levels of } \\
\text { improvisation and make } \\
\text { decisions quickly. }\end{array}$ & $\begin{array}{l}\text { Engage in moderate levels } \\
\text { of improvisation. }\end{array}$ & $\begin{array}{l}\text { Engage in moderate levels } \\
\text { of improvisation. }\end{array}$ & $\begin{array}{l}\text { Engage in low levels of } \\
\text { improvisation and make } \\
\text { decisions slowly. }\end{array}$ \\
\hline Performance & $\begin{array}{l}\text { High levels of performance on all } \\
\text { dimensions (customer, efficiency, } \\
\text { and financial). }\end{array}$ & $\begin{array}{l}\text { Moderately high } \\
\text { customer-based and low } \\
\text { efficiency- and financial-based } \\
\text { performance. }\end{array}$ & $\begin{array}{l}\text { Low customer-based and } \\
\text { moderately low efficiency- } \\
\text { and financial-based } \\
\text { performance. }\end{array}$ & $\begin{array}{l}\text { Low performance on all } \\
\text { dimensions. }\end{array}$ \\
\hline
\end{tabular}


the entirety of the environment. Exploring strategic complexity reveals the foundation upon which strategies are developed and increases knowledge of how firms build and sustain a competitive advantage.

Strategically organizations consider multiple perspectives in formulating strategy and produce superior customer-based performance. (For a fuller description, refer to Table 4). They had significantly higher financial performance than - (customer and competitor) oriented organizations, significantly higher efficiencyand financial-based performance than organizations (low on all strategic dimensions), and a positive standardized coefficient across all of the performance dimensions. Thus, integrating multiple dimensions translates into an advanced interpretive capability that produces superior performance.

The group's strategic focus is consistent with the extensively researched market orientation. This groupwhile more simple than the group-maintains both a competitive and customer orientation. This dual-oriented cognitive framework allows the firm to engage in moderate levels of multiple perspective consideration; however, this organizational cognitive type does not achieve superior performance relative to the

group. This is likely due to inattentiveness to the macroenvironmental trends that shape future customer needs, combined with a lack of emphasis on a product capability that translates customer requirements into superior product specifications. While the group does outperform the group on customer-based performance outcomes, the results would suggest that the long espoused market-oriented firm should consider expanding its focus to include the macro-environment and the product to further improve performance.

The cognitive form has not been identified in prior research. While Andrews and Smith (1996) offer a glimpse of the connection between knowledge of the macro-environment and marketing creativity, this research demonstrates that there are distinct organizations that focus primarily on broader trends. The marketing strategy making and performance of this group is no different than the group. However, this unidimensional cognitive framework leads to simplified strategic decision-making and an overall underperformance when compared to strategically complex organizations. For superior performance, organizations need to look both broadly at trends in the environment while not losing site of the firm's most immediate demands-customers, competitors, and products.

The group lacks a cohesive cognitive framework upon which decision-makers can make sense of the environment and develop effective strategies. For this organizational type, there exists no dominant logic upon which to frame strategy. Interestingly, the group performs as well as the and group on efficiency- and financial-based performance; however, this group lacks the group's customer and competitor focus required to achieve effective customer outcomes. The results are unequivocal in that organizations lacking a cognitive framework incorporating multiple environmental dimensions do not have the interpretive capability to outperform the group.

This research provides a preliminary examination of the decision processes and performance consequences of organizations that vary in their strategic complexity. Effective marketing strategy making and superior firm performance require recognition and consideration of multiple environmental demands. By expanding its sensemaking capacity, an organization is able to understand the diverse, interrelated, and often dialectical aspects of its environment and match this with an effective response.

Organizations operate in information environments that are, at times, ambiguous, uncertain, and dynamic. For managers, the situation is less an issue of too little information, than of too much. A key managerial task is to navigate the information rich waters, assess the situation, and deploy appropriate resources. Remaining competitive requires that firms rely on internal resources to process information better than rivals. Managers need to be aware of the possible costs associated with insufficient investment in the firm's interpretive capability.

This study reveals that strategically complex organizations consider multiple perspectives and engage in more involved decision-making. Organizations with a partial understanding of the environment seek stability and thus avoid information that might disconfirm the prevailing view. Organizations with a broad conceptualization are also able to improvise marketing strategies, but this ability is shared with firms that-while less complex-focus on either macro-environmental or market issues. Reactive organizations, in contrast, have no unifying focus or common understanding from which to act and are less able to improvise. Thus, seeing the environment as multifaceted leads to more exhaustive decision-making, but attuning to any one factor provides the requisite focus to both think and act, simultaneously.

Complex problems require a complex cognitive framework in order to effectively understand and respond to the situation. While strategically complex organizations outperform reactive organizations, macro-environmental and market-oriented organizations are in some ways equally effective. Macro-environmentally focused firms simply omit customer input in conceptualizing the environment, which explains their underperformance on the customer dimension. Interestingly, those organizations focusing on the market (i.e., competitor and customer dimensions) did not perform as well on customer outcomes. This is likely due to their disregard for the larger environment in which both customers and competitors operate. Thus, the firm 
may only become aware of broader trends once they have already affected customers and competitors. At which point, the organization has failed to anticipate changing demands.

This suggests that an emphasis on customers and competitors while disregarding product and broader environmental issues is insufficient. Yet with so many possible strategic considerations, organizations without the cognitive resources to maintain a complex understanding (or who choose to buffer their internal systems from the distractions of environmental change) might be tempted to limit the number of relevant dimensions. While such a strategy could minimize information overload, managers should recognize that doing so might also short-circuit the decision-making process and lessen customer outcomes.

This research is exploratory in nature. The study has sought to provide a preliminary test of the premise that strategically complex organizations with the capacity to absorb variety are more adaptive in their decision processes and achieve better performance outcomes. Single informants were used to provide a preliminary test of these propositions and the sample is not representative of all businesses. While multiple efforts were undertaken to ensure that respondents were qualified to respond on organizational issues, biases may be introduced based on the selective perception of the informants. The data were also collected from managers operating within the wholesale-distribution industry. While the results should hold in any context in which a group of individuals confront a complex task, additional tests using a broader sample would extend the generalizability of these results.

A cluster analysis revealed four distinct groups that varied based on their degree of strategic complexity. The theoretical question addressed sought to explore cognitive groups in order to demonstrate the effect of differences in complexity on marketing strategy and performance. However, this does not preclude the existence of other cognitive types. For instance, a firm may exhibit a financial orientation by conceptualizing situations based on return on investment. Additionally, other factors exist that may influence interpretation and behavior, such as suppliers, shareholders, and employees. There is some evidence of a positive relationship between considering multiple stakeholders and performance (Greenley and Foxall, 1997).

Future research could also examine the antecedents to strategic complexity. For instance, how might organizational factors, like structure and culture, affect the development of a complex strategic orientation? Antecedents might include a decentralized, less formalized organizational structure; an open, innovative culture; perception of a turbulent, highly competitive market environment; proactive, flexible top managers; open communication across individuals and units; and a myriad of other factors waiting to be identified.

The organizational learning literature could also be further linked to this study's findings. Huber (1991) discusses four components of organizational learning: knowledge acquisition, information distribution, information interpretation, and organizational memory. This paper has explored one component: interpretation. While interpretation has received little attention in the marketing literature, future research should embed this process within a fuller context. For instance, this study proposes that an organization's strategic complexity guides information processing, but how and when might newly learned information shape the structure of an organization's orientation? How might organizational learning and information flow among decision-makers lead to the development (or breakdown) of organizational understanding? Just as schemas are both inputs to and products of experience, what is the relationship between strategic complexity and memory? Answers to these questions would improve our understanding of organizational learning.

Strategic complexity may also be counterproductive under certain conditions. Future research could explore the efficacy of complexity during dynamic versus routine tasks or in ambiguous versus explicit environments. This begs the question: is there an optimal level of complexity? Schwenk (1984) argues that organizations may choose to simplify cognition in an effort to remain consistent with past strategies or to increase confidence and commitment with a chosen strategy. If so, the ability to modulate between simple and complex strategies based on situational (i.e., task/environment) demands would be a useful line of inquiry.

\section{Conclusion}

This paper responds to Walsh's (1995) call for research establishing a relationship between organizational cognition and action and specifically addresses Varadarajan and Jayachandran's (1999) request for research examining the role of organizational cognition and marketing strategy. Studying strategic complexity furthers our understanding of the processes by which organizations seek to make sense of their environment and the firm's role within it. By uncovering this process, we begin to explain how firms develop and deploy resources for creating and sustaining a competitive advantage, thus increasing our understanding of marketing capabilities (Day, 1994). Many questions remain for marketing scholars to explore, and more research needs to be done to clarify marketing's role in improving the organization's sense and response capabilities. 


\section{Appendix A. Study measures}

\section{a}

We target customers where we have an opportunity for competitive advantage. (removed)

We rapidly respond to competitive actions that threaten us.

Our salespeople regularly share information within our business concerning competitors' strategies.

Top management regularly discusses competitors' strengths and strategies.

We constantly monitor our level of commitment to serving customer's needs.

Our strategy for competitive advantage is based on our understanding of customers' needs.

Our business strategies are driven by our beliefs about how we can create greater value for customers.

We give close attention to after-sales service.

Our business objectives are driven primarily by customer satisfaction.

We measure customer satisfaction systematically and frequently.

We are always seeking ways to improve the delivery of our services.

Our organization is constantly seeking process improvements.

Our business objectives are driven towards producing the highest quality services.

In determining our strategic direction, we search for trends emerging outside our industry.

Our strategy includes converting trends outside our industry into business opportunities.

We detect changes in the outside environment before most other firms.

Our organizational objectives are directly influenced by trends outside our industry.

We pay close attention to conditions outside of our industry.

In developing marketing strategy, our organization: positions problems within multiple contexts. gives due consideration to divergent explanations of problems. reflects on problems from multiple vantagepoints. seeks solutions by considering a diverse set of perspectives relies on diverse information for finding solutions. discusses novel perspectives in seeking solutions. bases solutions on viewpoints from multiple organizational members. selects solutions using multiple perspectives. views each solution from all angles.

In our organization, strategic marketing action can be characterized as: Figured out as we went along-Followed an action plan Improvised-Strictly followed our plan Ad-libbed-Not ad-libbed

Customer satisfaction

Delivering customer value

Customer loyalty

Liquidity

Labor productivity

Cash flow
Appendix A (

)

Sales growth

Profit growth

Overall profitability

a Seven point agree-disagree scale.

b Seven point semantic differential scale.

c Seven point scale relative to other firms in industry.

\section{References}

Aaker DA. Strategic Market Management, vol. 6/e. New York: Wiley; 2001.

Andrews J, Smith DC. In search of the marketing imagination: factors affecting the creativity of marketing programs for mature products. J Mark Res 1996;33(May):174-87.

Ashby WR. An Introduction to Cybernetics. London: Chapman and Hall; 1956.

Barr PS. Adapting to unfamiliar environmental events: a look at the evolution of interpretation and its role in strategic change. Organ Sci 1998;9(6):644-69.

Boisot M, Child J. Organizations as adaptive systems in complex environments: the case of China. Organ Sci 1999;10(3):237-52.

Boulding W, Moore MC, Staelin R, Corfman KP, Dickson PR, Fitzsimons $\mathrm{G}$, et al. Understanding managers' strategic decision-making process. Mark Lett 1994;5(4):413-26.

Clark LA, Watson D. Constructing validity: basic issues in objective scale development. Psychol Assess 1995;7(3):309-19.

Daft RL, Weick KE. Toward a model of organizations as interpretation systems. Acad Manage Rev 1984;9(2):284-95.

Day GS. The capabilities of market-driven organizations. J Mark 1994; 58(October):37-52.

Day GS, Nedungadi P. Managerial representations of competitive advantage. J Mark 1994;58(April):31-44.

Day GS, Wensley R. Assessing advantage: a framework for diagnosing competitive superiority. J Mark 1988;52(April):1-20.

Deshpande R, Gatignon H. Competitive analysis. Mark Lett 1994;5(3): $271-87$.

Deshpande R, Farley JU, Webster FE. Corporate culture, customer orientation, and innovativeness in Japanese firms: a quadrad analysis. J Mark 1993;57(January):23-37.

Distribution Research and Education Foundation. Facing the Forces of Change: Four Trends Reshaping Wholesale Distribution. Washington (DC): DREF/NAW Publications; 1998

Driver MJ, Streufert S. Integrative complexity: an approach to individuals and groups as information-processing systems. Adm Sci Q 1969;14: $272-85$.

Fornell C, Larcker DF. Evaluating structural equation models with unobservable variables and measurement error. J Mark Res 1981; 18(February):39-50.

Gatignon H, Xuereb JM. Strategic orientation of the firm and new product performance. J Mark Res 1997;34(February):77-90.

Greenley GE, Foxall GR. Multiple stakeholder orientation in UK companies and the implications for company performance. J Manag Stud 1997;34(2):259-84

Hair JH, Anderson RE, Tatham RL, Black WC. Multivariate Data Analysis. 5th ed. Englewood Cliffs (NJ): Prentice Hall; 1998.

Huber GP. Organizational learning: the contributing processes and the literatures. Organ Sci 1991;2(1):88-115.

Jacobson R, Aaker DA. The strategic role of product quality. J Mark 1987; 51(October):31-44.

Kohli AK, Jaworski BJ, Kumar A. MARKOR: a measure of market orientation. J Mark Res 1993;30(4):467-77.

Lusch RF, Brown JR. Interdependency, contracting, and relational behavior in marketing channels. J Mark 1996;60(October):19-38. 
Lyles MA, Schwenk CR. Top management, strategy, and organizational knowledge structures. J Manag Stud 1992;29(2):155-74.

McGill AR, Johnson MD, Bantel KA. Cognitive complexity and conformity: effects on performance in a turbulent environment. Psychol Rep 1994;75:1451-72.

Menon A, Bharadwaj SG, Adidam PT, Edison SW. Antecedents and consequences of marketing strategy making: a model and a test. J Mark 1999;63(2):18-40.

Miller CC, Burke LM, Glick WH. Cognitive diversity among upperechelon executives: implications for strategic decision processes. Strateg Manage J 1998;19:39-58.

Milligan GW, Cooper MC. Methodology review: clustering methods. Appl Psychol Meas 1987;11(4):329-54.

Milliken FJ, Martins LL. Searching for common threads: understanding the multiple effects of diversity in organizational groups. Acad Manage Rev 1996;21(2):402-33.

Mintzberg H, Raisinghani D, Theoret A. The structure of 'unstructured' decision processes. Adm Sci Q 1976;21:246-75.

Moorman C, Miner AS. The convergence of planning and execution: improvisation in new product development. J Mark 1998;62(3):1-20.

Morgan NA, Piercy NF. Interactions between marketing and quality at the sbu level: influences and outcomes. J Acad Mark Sci 1998;26(3): $190-208$.

Naman JL, Slevin DP. Entrepreneurship and the concept of fit: a model and empirical tests. Strateg Manage J 1993;14:137-53.

Narver JC, Slater SF. The effect of a market orientation on business profitability. J Mark 1990;54(October):20-35.

Neisser U. Cognition and Reality. San Francisco: W.H. Freeman and Company; 1976.

Netemeyer RG, Bearden WO, Sharma S. Scaling Procedures: Issues and Applications. Thousand Oaks (CA): Sage; 2003.

Noble CH, Sinha RK, Kumar A. Market orientation and alternative strategic orientations: a longitudinal assessment of performance implications. J Mark 2002;66(4):25-39.

Parasuraman A, Zeithaml VA, Berry LL. A conceptual model of service quality and its implications for future research. J Mark 1985;49(Fall): $41-50$.

Phillips LW. Assessing measurement error in key informant reports: a methodological note on organizational analysis in marketing. J Mark Res 1981;18(November):395-415.

Piercy NF. Marketing implementation: the implications of marketing paradigm weakness for the strategy execution process. J Acad Mark Sci 1998;26(3):222-36.
Prahalad CK, Bettis RA. The dominant logic: a new linkage between diversity and performance. Strateg Manage J 1986;7:485-501.

Raykov T, Widaman KF. Issues in applied structural equation modeling research. Struct Equ Modeling 1995;2(4):289-318.

Schwenk CR. Cognitive simplification processes in strategic decisionmaking. Strateg Manage J 1984;5:111-28.

Schwenk CR. The cognitive perspective on strategic decision making. J Manag Stud 1988;25(1):41-55.

Siguaw JA, Simpson PM, Baker TL. Effects of supplier market orientation on distributor market orientation and the channel relationship: the distributor perspective. J Mark 1998;62(July):99-111.

Sinkula JM. Market information processing and organizational learning. J Mark 1994;58(1):35-45.

Streufert S, Nogami GY. Cognitive style and complexity: implications for I/O psychology. In: Cooper CL, Roverston L, editors. International Review of Industrial and Organizational Psychology. Chichester (NY): Wiley; 1989. p. 93-143.

Streufert S, Swezey RW. Complexity, Managers, and Organizations. Orlando (FL): Academic Press; 1986.

Urbany JE, Montgomery DB. Rational strategic reasoning: an unnatural act? Mark Lett 1998;9(3):285-99.

Varadarajan PR, Jayachandran S. Marketing strategy: an assessment of the state of the field and outlook. J Acad Mark Sci 1999;27(2):120-43.

Voss GB, Voss ZG. Strategic orientation and firm performance in an artistic environment. J Mark 2000;64(January):67-83.

Walker OC, Ruekert RW. Marketing's role in the implementation of business strategies: a critical review and conceptual framework. J Mark 1987;51(July):15-33.

Wally S, Baum JR. Personal and structural determinants of the pace of strategic decision making. Acad Manage J 1994;37(4):932-56.

Walsh JP. Selectivity and selective perception: an investigation of managers' belief structures and information processing. Acad Manage J 1988; 31(4):873-96.

Walsh JP. Managerial and organizational cognition: notes from a trip down memory lane. Organ Sci 1995;6(3):280-321.

Weick KE. Sensemaking in Organizations. Thousand Oaks (CA): Sage Publications; 1995.

Weick KE, Daft RL. The effectiveness of interpretation systems. In: Cameron DA, Whetten DA, editors. Organizational Effectiveness: A Comparison of Multiple Models. New York: Academic Press; 1983. p. 71-93.

Wright P, Kroll M, Chan P, Hamel K. Strategic profiles and performance: an empirical test of select key propositions. J Acad Mark Sci 1991;19(3): $245-54$. 